\title{
Música e cibercultura
}

RESUMO

O desenvolvimento das tecnologias digitais muda as formas de produzir informação e o que se produz. A convergência tecnológica elimina limites entre mídias, tornando-as solidárias em termos operacionais, e erodindo relações com produtores e usuários. A Internet permite que qualquer um funcione como produtor, mediador e usuário de conteúdos. A música está vivendo profundas mudanças nos seus modos de produção, difusão e uso. A cena musical moderna era vinculada às séries da indústria cultural e a cultura de massas. A música popular moderna tem a forma de canções reproduzidas pelo fonógrafo, que se difundem pelo rádio, já a música na cibercultura está vinculada às novas tecnologias. A música digital tem a forma potencial de obra aberta, compactada sob a forma de arquivo MP3, fluindo nos MP3 players, celulares e Internet.

\section{PALAVRAS-CHAVE}

cibercultura

música

convergência tecnológica

\section{ABSTRACT}

The development of the digital technologies is seedling the producing information forms and what is produced. The technological convergence eliminates limits among media, turning them solidarity into operational terms, and causing erosion in the relationships among producers and users. Internet allows any one to work as producer, mediator and users of contents. The music is living deep changes in their production manners, diffusion and use. The modern musical scene was linked to the series of the cultural industry the mass culture. The modern popular music has the form of songs reproduced by the phonograph, diffused by the radio. The music in the cyberculture is linked with new technologies. The digital music has the potential form of open source compacted under the MP3 file form, flowing in MP3 players, cellulars and Internet.

\section{KEY WORDS}

cyberculture

music

technological convergence

\section{Clóvis Ricardo Montenegro de Lima}

Professor do Departamento de Ciência da Informação da UFSC/SC/BR clovis.mlima@uol.com.br

\section{Rose Marie Santini}

Doutoranda em Ciência da Informação pelo IBICT/UFF e em Comunicação e Cultura pela UFRJ/RJ/BR

mariesantini@gmail.com
No final do século $X X$ iniciam-se globalmente mudanças históricas que desmantelam muitas configurações sociais que marcam a Modernidade. Há mudanças nos regulamentos econômicos e sociais, a reestruturação de formas organizacionais, a quebra de representações e expectativas. Há atualmente maior incerteza em relação ao futuro e enfraquecimento dos vínculos e das solidariedades sociais do trabalho.

Os processos de produção da informação e do conhecimento também mudam. Ganha maior dimensão a produção de informação e de conhecimento intensivos, de produtos personalizados, e de signos e imagens, em contraposição a produção de bens materiais padronizados. As características da sociedade industrial perdem força com a flexibilização globalizada das formas de organização social. A convergência de mudanças sociais e tecnológicas produz mudança nas relações de produção econômica e de conhecimento. O processo social de desenvolvimento científico e tecnológico tem implicações culturais e políticas cumulativas, que mudam as formas de discutir, produzir e organizar informação, enfim, de agir e de representar a sociedade.

Castells (2001) observa que cada modo de desenvolvimento é definido pelo elemento fundamental à promoção da produtividade no processo de produção. No modo de desenvolvimento industrial, a principal fonte de produtividade se encontra na introdução de novas fontes de energia e na capacidade de descentralização do uso de energia ao longo dos processos de produção e de circulação. Na sociedade da informação a fonte de produtividade se encontra na tecnologia de geração de conhecimentos, de processamento da informação e de comunicação de símbolos.

O elemento essencial para a construção da sociedade da informação no Brasil, de acordo com Miranda (2000), é a implantação de uma sólida plataforma de telecomunicações, na qual possam difundir-se e florescer as aplicações em áreas de denso conteúdo e de retorno social. Isto requer a instalação e fortalecimento de adequada infra-estrutura de escolas, bibliotecas e laboratórios, a fim de que uma nova geração de brasileiros se prepare para o futuro.

A sociedade da informação se desenvolve através da operação de conteúdos sobre a infra-estrutura de conectividade. Miranda (2000) afirma que o fenômeno que melhor caracteriza o funcionamento em rede é a convergência progressiva que ocorre entre produtores, intermediários e usuários em torno de recursos, produtos e serviços de informação afins.

Uma das contribuições mais relevantes da Internet é permitir que qualquer usuário venha a ser produtor, 
intermediário e usuário de conteúdos. O alcance dos conteúdos é universal, resguardadas as barreiras lingüísticas e tecnológicas do processo de difusão. É por meio da operação de redes de conteúdos de forma generalizada que a sociedade atual vai se mover para a sociedade da informação.

A Internet inclui as pessoas não somente como receptores passivos, mas também como agentes ativos e determinantes, livres para escolherem o conteúdo, interagirem com ele, independentemente do espaço e do tempo em que se localizam o usuário e os conteúdos. A Internet enriqueceu o papel do usuário, do cidadão, dotando-o com o potencial e a capacidade de produtor e intermediário de conteúdos (Miranda, 2000).

A convergência tecnológica vem eliminando os limites entre os meios de comunicação, tornandoos solidários em termos operacionais, e erodindo as tradicionais relações que mantinham entre si e com seus usuários. A tecnologia digital torna possível o uso de uma linguagem comum: tudo pode ser transformado em dígitos e distribuído por fios telefônicos, fibras óticas e satélites ou ainda por via de um meio físico de gravação, como discos digitais ou pen-drive. A digitalização torna o conteúdo totalmente plástico, isto é, qualquer mensagem, som ou imagem pode ser editada, mudando de uma forma e suporte.

A técnica participa ativamente da ordem cultural, afirma Lévy (1993). Quando uma circunstância, como a mudança técnica, desestabiliza o antigo equilíbrio das forças e das representações, estratégias inéditas e alianças inusitadas tornam-se possíveis. Uma infinidade de agentes sociais explora as novas possibilidades, antes que uma nova situação se estabilize provisoriamente, com seus valores e sua cultura locais. Usando uma expressão de Lévy: a técnica é uma "caixa de Pandora metafísica".

Lévy (1993) pensa que a presença ou a ausência de certas técnicas fundamentais da comunicação permite classificar as culturas em algumas categorias gerais. Esta classificação apenas auxilia a localizar os pólos da história. Não deve fazer com que se esqueça que cada grupo social, em dado instante, encontra-se em situação singular e transitória frente às tecnologias intelectuais.

Os pólos da oralidade, da escrita e da informática não são eras, e, observa Lévy (1993), não correspondem a épocas determinadas. A cada instante e a cada lugar os três pólos estão sempre presentes, mas com intensidade variável. $\mathrm{O}$ uso de um determinado tipo de tecnologia intelectual coloca ênfase particular em certos valores, certas dimensões da atividade cognitiva ou imagem social do tempo, que se tornam então mais explicitamente focadas e discutidas e ao redor dos quais se cristalizam formas culturais particulares.

Quando descreve e discute a formação cultural atual, que denomina de cibercultura, Lévy (1999) afirma que existem três grandes etapas da história da cultura: a das sociedades fechadas, de cultura oral; a das sociedades civilizadas, usuárias da escrita; e a da cibercultura, que corresponde a globalização concreta das sociedades. Cabe observar que ele sublinha que a segunda e a terceira etapa não eliminam a anterior: relativizam-na, acrescentando-lhe dimensões suplementares.

$\mathrm{O}$ quadro 1 apresenta alguns processos de deslocamento dos meios de comunicação e da cultura musical da modernidade para a sociedade da informação. A cena musical moderna está profundamente vinculada às séries da indústria cultural e a cultura de massas. A música popular moderna tem a forma de canções, que são reproduzidas pelo fonógrafo e se difundem pelo rádio e televisão. Os discos de vinil registram as celebridades e as estrelas populares. Os toca-discos ocupam espaço na casa das famílias modernas. Na cultura moderna a indústria fonográfica produz e vende milhões de discos em série.

\section{Quadro 1. Comunicação e cultura musical na Modernidade e na Sociedade da Informação}

\begin{tabular}{|c|c|c|}
\hline & Modernidade & Sociedade da Informação \\
\hline Tempo do espírito & Escrita & Informática \\
\hline Produto & $\begin{array}{l}\text { Música popular, } \\
\text { canções }\end{array}$ & $\begin{array}{l}\text { Música eletrônica, } \\
\text { obra aberta, colagens }\end{array}$ \\
\hline Tecnologia & $\begin{array}{l}\text { Instrumentos } \\
\text { elétricos, Fonógrafo }\end{array}$ & $\begin{array}{l}\text { Computadores, } \\
\text { Softwares, MP3 player }\end{array}$ \\
\hline Registro & $\begin{array}{l}\text { Analógico: } \\
\text { cilindro, vinil, } \\
\text { fita magnética }\end{array}$ & $\begin{array}{l}\text { Digital: } \\
\text { CD, DVD, MP3 }\end{array}$ \\
\hline Meios de difusão & Rádio e TV & Internet, telefone celular \\
\hline Comunicação e Cultura & $\begin{array}{l}\text { Industria cultural, } \\
\text { cultura de massa }\end{array}$ & $\begin{array}{l}\text { Cibercultura, } \\
\text { redes colaborativas }\end{array}$ \\
\hline
\end{tabular}

A cena musical da sociedade da informação está profundamente vinculada às novas tecnologias de informação e comunicação. A música eletrônica tem a forma de obra aberta, compactadas sob a forma de arquivo MP3 e fluindo no espaço virtual da Internet. A criatividade coletiva registra as suas colagens sonoras. Os CDs e os DVDs são formas transitórias de armazenamento de música. Os aparelhos que tocam MP3 são o atual objeto de desejo de milhões em todo o mundo. A música se dissemina na internet. Vivemos a expansão das web-rádios, sites de compartilhamento e redes $\mathrm{P} 2 \mathrm{P}$.

Lévy (1993) adverte que nos falta recuo para avaliar de forma plena todas as conseqüências das mutações tecnológicas sobre a produção e a economia da música atual, sobre as práticas musicais e a aparição de novos gêneros. Cabe mencionar que a maior parte dos observadores está de acordo quanto a ver na emergência dos instrumentos e dos meios eletrônicos e digitais uma ruptura comparável a da invenção da notação ou ao surgimento do disco de vinil. 


\section{Comunicação e cibercultura}

A cibercultura é o conjunto de processos tecnológicos e sociais emergentes a partir da década de 70 do século $\mathrm{XX}$, com a convergência das telecomunicações, da informática e da sociabilidade contra-cultural da época (Breton, 1990; Castells, 2001), que tem enriquecido a diversidade cultural mundial e proporcionado a emergência de culturas locais em meio ao global supostamente homogeneizante. Uma das principais características dessa cibercultura planetária é o compartilhamento de arquivos, música, fotos, filmes, etc., construindo processos coletivos (Lemos, 2004).

Assistimos a emergência de novas práticas comunicacionais no ciberespaço (e-mails, listas, sites de relacionamentos, weblogs, webcams, icq, chats), da arte eletrônica, de novas formas de ação política (cibercidadania, ciberativismo, hackers), transformações culturais e éticas (softwares livres, redes $\mathrm{P} 2 \mathrm{P}$, políticas de privacidade) e uma nova configuração comunicacional (liberação do pólo da emissão) nos ambientes digitais de comunicação.

A cibercultura pode ser compreendida como processo sócio-técnico da atualidade, marcada basicamente por redes telemáticas, sociabilidade online e navegação planetária em busca de informação (Lemos; Cunha, 2003). A cultura contemporânea está marcada pela interação comunicacional. A cibercultura não é determinada pela tecnologia: tratase de uma relação que se estabelece pela emergência de novas formações sociais e tecnologias digitais. Não se trata de determinismo tecnológico, isto é, de nomear épocas históricas pelos seus respectivos conjuntos de artefatos, mas sim de fenômeno social que possui potencialidades e negatividades a partir das tecnologias contemporâneas.

Quando tratamos das questões relacionadas à música na cibercultura, podemos pensar no grau de penetração da Internet no mundo, e principalmente no Brasil, que ainda é restrita. Não foi diferente em relação aos outros meios de comunicação. Quando o rádio ou a televisão surge, seu acesso era um privilégio de poucos. Atualmente rádio e TV possuem penetração de aproximadamente $95 \%$ na população brasileira.

Em relação ao suportes utilizados pela indústria cultural da música, por exemplo, percebemos claramente que os ciclos de vida do vinil, da fita magnética ou do CD duram de 15 a 25 anos, e assim surgem sempre novos formatos para uso cultural, o que leva a "reconfiguração" dos suportes anteriores. Constatamos que as novas tecnologias provocam ações e reações significativas, que geram adequações e novas formas de uso de recursos existentes.

Emerge na cibercultura uma Mass SelfCommunication (Castells, 2006) que está presente na Internet e também no desenvolvimento dos telefones celulares. Estimase que existem atualmente mais de um bilhão de usuários de internet e cerca de dois bilhões de linhas de telefonia celular no mundo. Um terço da população do planeta pode se comunicar graças aos telefones celulares, inclusive em lugares onde não há energia elétrica nem linhas de telefone fixo. Em pouco tempo houve a explosão de novas formas de comunicação. As pessoas desenvolveram seus próprios sistemas: o SMS, os blogs, sistemas P2P, o skype, entre outros.

$\mathrm{O}$ Peer-to-Peer ou $\mathrm{P}_{2} \mathrm{P}^{1}$ torna possível a transferência de qualquer dado digitalizado, principalmente a música. Em maio de 2006, havia 37 milhões de blogs (em janeiro de 2006, havia 26 milhões). Em média, um blog é criado por segundo no mundo, o que significa 30 milhões por ano. Aproximadamente 55\% dos blogueiros continuam a alimentar seus blogs até três meses depois deles terem sido abertos. A quantidade de blogueiros é 60 vezes maior do que era há seis anos. E ele dobra de seis em seis meses (Castells, 2006).

\section{Música: da cultura de massas a cibercultura}

$\mathrm{O}$ conceito de indústria cultural foi originalmente elaborado por Adorno e Horkheimer (1970) na década de 1930, a partir de suas impressões das indústrias fonográficas e do cinema. Eles vivem na época em que a produção em larga escala, baseada na racionalização e na divisão social do trabalho, promove uma desarticulação das formas de vida anteriores. A industrialização se introduz também nas artes e na cultura, especialmente com a invenção do fonógrafo e das máquinas do cinema.

\section{A música na era digital vive uma grande reorganização das práticas de criação e difusão}

Adorno (1999) se interessou pela passagem da audição de uma execução musical por artistas para a audição da mesma música por meio do fonógrafo. $\mathrm{O}$ uso deste meio mecânico para multiplicar a audição musical que lhe sugere a expressão "indústria cultural". Esses filósofos se voltam contra o uso de meios mecânicos de transmissão musical, pois pensam que a qualidade de composição e interpretação deve ser observada na comunicação com o público, e contra a intermediação cultural.

A cultura de massas não pode ser considerada uma arte que nasce de modo espontâneo, diz Adorno (1999). Na era industrial, "as massas" não conhecem nada além da obrigação de se distrair e de relaxar, como parte do necessário processo de recriar a força de trabalho esgotada. O modo de produção capitalista determina a deterioração da cultura e da arte. A indústria cultural subordina os elementos da cultura, da arte e do divertimento. 
A comunicação, a arte e a cultura sofrem profunda reorganização com $\mathrm{o}$ aparecimento das novas tecnologias digitais. As máquinas e os suportes eletrônicos de produção, de armazenamento e de difundir induziram a profundas transformações na forma de produzir e no que se produz. A música na era digital vive uma grande reorganização das práticas de criação e difusão. Há uma mudança no uso e na disseminação da linguagem musical (Santini, 2005).

A Internet altera o modo de fazer e experimentar a cultura. O caráter hiper-midiático da web promoveu a "virtualização da música" de modo muito especial, amparada na sua digitalização. Isto significa dizer que qualquer obra musical é passível de produção, compactação e difusão à maneira de um arquivo de texto ou imagem digital. A "cibercultura" - isto é, a sinergia entre a esfera tecnológica das redes de comunicação e a sociocultural - imprimiu um redimensionamento ao mundo da música advindas das técnicas de compressão em arquivos de áudio (Lévy, 1999).

A transmissão de arquivos musicais na Internet muda as relações entre produtores e usuários de música. Por um lado, os produtores de música podem disseminar com facilidade a sua obra, tornando-a virtualmente acessível a milhões de pessoas sem grandes custos de distribuição. Por outro lado, os usuários podem recuperar e usar arquivos musicais sem depender da mediação da indústria fonográfica. A possibilidade de que a música circule sem um suporte físico faz com que produtores e usuários dependam menos da intermediação da indústria fonográfica. As máquinas e seus mecanismos de busca ampliam as possibilidades de encontro entre público, obras e autores (Santini, 2005).

A necessidade de simplificar o uso dos arquivos digitais musicais recuperados através da Internet faz surgir dispositivos para sua reprodução. A facilidade de recuperar os arquivos da Internet (download) e produzir unidades personalizadas de armazenamento trouxe importantes mudanças na relação dos usuários com o mundo da música. A unidade conceitual do álbum ou $\mathrm{CD}$ com menos de uma hora de música é substituída pela possibilidade de arquivar milhares de músicas, escolhidas aleatoriamente, em um pequeno tocador portátil de MP3. O usuário atual quer as facilidades proporcionadas pelas novas tecnologias e carregar todas as canções preferidas tornou-se viável e cômodo. Forma-se uma cultura de uso da música muito particular na cibercultura.

A recuperação e o uso das informações dos arquivos digitais de áudio estão muito facilitados e isto coloca em questão os modelos de uso produzidos pela indústria fonográfica. Há perplexidade das grandes gravadoras em relação ao aumento explosivo da disseminação de arquivos de música, através do download e da transmissão de canções nas rádios on- line. As grandes empresas da indústria fonográfica parecem não ter percebido o enorme potencial da Internet na difusão dos bens culturais, focando apenas os aspectos comerciais negativos (Santini, 2005).

A Internet articula virtualmente uma musicoteca, potencialmente sem limites. A facilidade de inserir os arquivos, de fazê-los circularem, de compartilhá-los e de recuperá-los muda os processos de difusão e de uso da música. As grandes gravadoras perderam o controle do que pode ser gravado, distribuído e usado. A história da circulação de arquivos digitais de música através da Internet está apenas começando.

\section{A cultura comunitária virtual acrescenta dimensão social ao compartilhamento de conteúdos, fazendo da Internet um meio de integração social e simbólica}

$\mathrm{Na}$ Internet o papel mediador das grandes gravadoras é posto em xeque, encurtando o caminho entre o artista e o público: cada vez mais artistas produzem sem vínculos com a indústria fonográfica. O barateamento e a descentralização da produção estúdios, editoras, gráficas e distribuidoras menores surgem em grandes quantidades para atender a demanda dos artistas independentes - possibilitam a músicos e intérpretes maior autonomia para produção e distribuição de suas obras.

As inovações tecnológicas modificam as formas de uso da música. O download de canções e o compartilhamento de arquivos na Internet se popularizam, facilitando a escolha dos ouvintes. Aumenta o valor da experimentação como uma etapa importante no processo de uso da música. O usuário de música se coloca numa posição privilegiada com a Internet: navegando na rede, o usuário pode escolher e experimentar, dentre os mais variados gostos, as canções que quer ouvir, na hora que melhor lhe convier, dispensando, dentro de alguns limites, a intermediação da indústria da música.

As conexões de alta velocidade (banda larga) estão cada vez mais acessíveis, abrindo espaço ao tráfego limpo e ininterrupto de sons e imagens. Não só usuários, mas também produtores independentes estão otimistas: músicos ignorados pela indústria cultural divulgam e compartilham canções na rede. As opções de uso crescem à medida que a quantidade de produções aumenta significativamente, devido ao barateamento das novas tecnologias de produção, difusão e uso da música. 
Além da diversidade e da possibilidade de experimentação, outro aspecto que se mostra extremamente relevante no uso da música através da Internet é o grau potencial de intervenção. Os suportes tradicionais de informação - como livro, disco, filmes - oferecem algumas possibilidades de intervenção: pode-se avançar e retornar sobre um mesmo trecho de um romance, repetir uma certa cena de um vídeo ou diminuir o volume de um disco ou um CD. Estas parecem limitadas em termos de intervenção se comparadas àquelas que se tornam possíveis com a utilização do computador.

A conseqüência direta dos conceitos de simulação e virtualidade em relação às informações digitais é a possibilidade de intervir tanto no nível organizacional como no nível estrutural das informações. Os computadores oferecem ferramentas que possibilitam ao usuário controle maior sobre as informações disponíveis. Essas ferramentas possuem recursos de busca, seleção, edição ou classificação, que são inviáveis em outros meios como livros e discos tradicionais.

O caráter potencial dos dados audíveis digitais faz com que o usuário possa manipulá-los, transformálos ou recriá-los de maneiras diversas, alterando assim os próprios signos originalmente codificados. A intervenção digital modifica a forma de usufruir a cultura: a experimentação digital da música pode resultar na própria transformação estética dos produtos oferecidos na cibercultura.

É cedo para apostar que a Internet libertará os bens culturais de quaisquer influências da indústria cultural, mas parece adequado esperar mudança na correlação de forças - dessa vez a favor dos usuários. Enquanto a indústria da música - particularmente as grandes gravadoras e os seus artistas - se debatem na perplexidade de não saber como agir diante do MP3 e da cibercultura, artistas e usuários incluem cada vez mais as novas tecnologias em suas vidas.

A indústria cultural enfrenta grandes desafios na sociedade da informação: a proteção do conteúdo digital; derrotar a pirataria e procurar manter lucrativos os seus negócios com a venda de produtos. Os executivos da indústria cultural têm se preocupado mais em criar mecanismos de proteção contra as cópias do que em encontrar alternativas para venda de seus produtos. Na visão das empresas a pirataria e os serviços de compartilhamento de conteúdos (redes P2P) são os grandes culpados pela crise.

As forças sócio-culturais da Internet não se reduzem às inovações tecnológicas. $\mathrm{O}$ uso das máquinas e softwares representa adesão a formas específicas de compartilhamento de informação e conhecimento. Os usuários de computadores interconectados estabelecem relações e criam comunidades virtuais. Estas relações e comunidades moldam o comportamento e a organização social em rede. A cultura comunitária virtual acrescenta dimensão social ao compartilhamento de conteúdos, fazendo da Internet um meio de integração social e simbólica.

\section{Considerações finais}

A cibercultura emergeem torno das novas tecnologias de informação e comunicação, especialmente da Internet, e inclui compartilhamento de informação e formas colaborativas de produção criativa. Destacase o caso da música, que está na vanguarda deste processo de mudança cultural. As transformações que se presencia em relação à música na Internet são análogas às transformações que se intensificam em relação a outros produtos culturais, como o livro e o filme.

\section{A cibercultura viabiliza novos} processos colaborativos de produção e compartilhamentos de informação, mudando as formações socioculturais, políticas e econômicas

A digitalização dos conteúdos e suportes facilita e potencializa o compartilhamento de bens simbólicos. Observa-se que a cibercultura cria forma própria de uso da música, produzida pela interação entre tecnologias digitais e formas solidárias e colaborativas de sociabilidade. O fenômeno da música na Internet é complexo e funciona por adição e multiplicação das formas de produzir, compartilhar, recuperar e usar conteúdos culturais na sociedade da informação. A indústria fonográfica decai, investindo nas trilhas sonoras do cinema, produzindo catálogos de DVDs, comercializando ringtones, etc.

A Internet potencializa abertura e liberação da produção, que marcam a cultura da rede: chats, orkut, weblogs, podcast, peer-to-peer para compartilhamento de música,imagens, filmesetextos. Aindústriaculturalestá em grave crise. A cibercultura viabiliza novos processos colaborativos de produção e compartilhamentos de informação, mudando as formações socioculturais, políticas e econômicas $\square$ Famecos

\section{NOTAS}

1 P2P designa um modelo de rede de informática onde os elementos (ou nós) não têm um papel exclusivo de cliente ou servidor. Funcionam das duas maneiras, sendo ora cliente ora servidor dos demais nós dessa rede, contrariamente aos sistemas do tipo "clienteservidor", no sentido comum do termo. Disponível em: <http://pt.wikipedia.org/wiki/P2P>. 


\section{REFERÊNCIAS}

ADORNO, Theodor W. O Fetichismo na Música e a Regressão da Audição. Os pensadores. São Paulo: Editora Abril, 1999.

BARROS, Monique Pereira Ibitinga. Futuro da Indústria Fonográfica Brasileira Diante da Pirataria e da Música Digital. 2003. Dissertação (mestrado) - PUC-Rio, 2003.

BARBROOK, Richard. Media Freedom: the contradictions of communications in the age of modernity. Londres: Pluto, 2003.

BRETON, Philippe. Une historie de l'informatique. Paris: Seuil, 1990.

CASTELLS, Manuel. A sociedade em rede. 5 ed. São Paulo: Paz e Terra, 2001.

. A era da intercomunicação. Le monde diplomatique, ago. 2006. Disponível em: <http://diplo.uol.com.br/2006-08,a1379>. Acesso em: 16 ago. 2006.

CASTRO, Gisela. Música, Tecnologia, Escuta \& Comunicação: as canções inumanas. 2003. Tese (doutorado) - ECO-UFRJ, 2003.

GONZÁLEZ DE GOMEZ, Maneira Nelida. Novos cenários políticos para a informação. Ci. Inf., Brasília, n.1, v.31, p. 27-40, jan. 2002.

LEMOS, André. Cibercultura, cultura e identidade: em direção a uma cultura "copyleft". Contemporânea - Revista de Comunicação e Cultura. Salvador, n. 2, vol. 2, p. 09-22, dez. 2004.

. Podcast: emissão sonora, futuro do rádio e cibercultura. 404nOtF0und, n. 46, jun. 2005. Disponível em: <http://www.facom.ufba.br/ ciberpesquisa/404nOtF0und/404_46.htm> Acessoem : 17 ago. 2006.

LEMOS, André; CUNHA, Paulo (Orgs). Olhares sobre a cibercultura. Porto Alegre: Sulina, 2003.

LESSIG, Lawrence. Cultura Livre: como a grande mídia usa a tecnologia e a lei para bloquear a cultura e controlar a criatividade. São Paulo: Trama, 2005.

LEVY, Pierre. Cibercultura. Rio de Janeiro: Editora 34, 1999.

. Tecnologias da Inteligência: o futuro do pensamento na Era da Informática. Rio de Janeiro: Editora 34, 1993.

LIMA, Clovis Ricardo Montenegro; SANTINI, Rose Marie. MP3 - música, comunicação e cultura. Rio de Janeiro: Epapers, 2006.

MATTELART, Armand; MATTELART, Michele. Pensar as mídias. São Paulo: Loyola, 2004.

MIRANDA, Antonio. Sociedade da informação: globalização, identidade cultural e conteúdos. Ci. Inf., Brasília, n. 2, v. 29, p.78-88, mai/ago. 2000.

MUGGIATI, Roberto. Rock, o grito e o mito: a música pop como forma de comunicação e contracultura. Petrópolis: Vozes, 1981

PELLANDA, Nice Maria Campos, et al. (Orgs.). Inclusão digital: tecendo redes afetivas/ cognitivas. Rio de Janeiro: DPA, 2005.

PRADO, C.; CAMINATI, F.; NOVAES, T. Sinapse XXI: novos paradigmas em comunicação. In: BARBOSA FILHO, A.; CASTRO, C.; TOME, T. (Orgs.). Mídias Digitais: convergência tecnológica e inclusão social. São Paulo: Paulinas, 2005.

SANTINI, Rose Marie. Admirável Chip novo: a música na era da Internet. Rio de Janeiro: Epapers, 2005.

STALLMAN, Richard. O projeto GNU. DataGramaZero - Revista de Ciência da Informação. Rio de Janeiro, n.1, fev. 2000.

WERTHEIN, Jorge. A Sociedade da Informação e seus desafios. DataGramaZero - Revista de Ciência da Informação. Rio de Janeiro, n.2, v.29, p. 71-22, mai/ago. 2000. 